\title{
Calcium-dependent subthreshold fluctuations in membrane voltage; a modeling study
}

\author{
David A Stanley ${ }^{1,2}$, Berj L Bardakjian ${ }^{2 *}$, Mark L Spano ${ }^{3}$, William L Ditto ${ }^{1}$ \\ From Nineteenth Annual Computational Neuroscience Meeting: CNS*2010 \\ San Antonio, TX, USA. 24-30 July 2010
}

Membrane potential noise plays multiple functional roles in the nervous system, as described in the review by Faisal et al [1]. Calcium-dependent potassium $\left(\mathrm{K}_{\mathrm{Ca}}\right)$ channels are ion channels whose conductance depends on intracellular calcium concentration. Previous work by Diba et al suggests that such channels play a central role in subthreshold voltage noise [2]. While most channels generate noise through their inherent thermal fluctuations, we hypothesize that $\mathrm{K}_{\mathrm{Ca}}$ channels also generate low-frequency subthreshold oscillations by transmitting stochastic fluctuations in intracellular calcium.

\section{Methods}

We have produced a stochastic computer model that incorporates $\mathrm{K}_{\mathrm{Ca}}$ channels and calcium dynamics into a

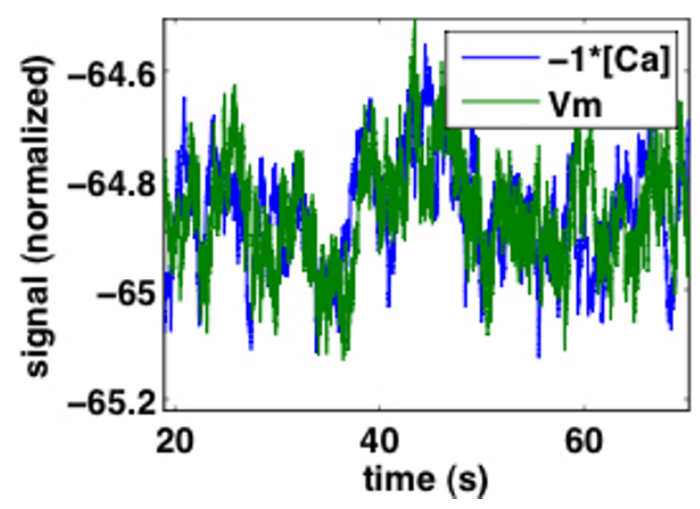

Figure 1 Relationship between intracellular calcium and membrane voltage. Intracellular calcium (blue, arb units) is inverted and scaled to show anti-correlation with membrane voltage (green). (Correlation coefficient $-56.4 \%$, Vm phase lag $\sim 600 \mathrm{~ms}$, Traub model default parameters.)

* Correspondence: berj@cbl.utoronto.ca

${ }^{2}$ Institute of Biomaterials and Biomedical Engineering, University of Toronto, Toronto, Ontario, Canada, M5S 3 G9
CA3 pyramidal neuron, which is based on the biophysically realistic Traub model [3]. To introduce channel noise, we replaced all Hodgkin-Huxley $(\mathrm{HH})$ channels with equivalent Markov models [4]. There is also an intracellular calcium pool, with $\mathrm{Ca}^{2+}$ levels that vary stochastically due to influx through Markovian calcium channels.

\section{Results}

Preliminary simulation results show that, for the default parameters used by Traub, there is anti-correlation between intracellular calcium and membrane voltage (Figure 1); this suggests intracellular calcium fluctuations may partially drive low-frequency voltage noise.

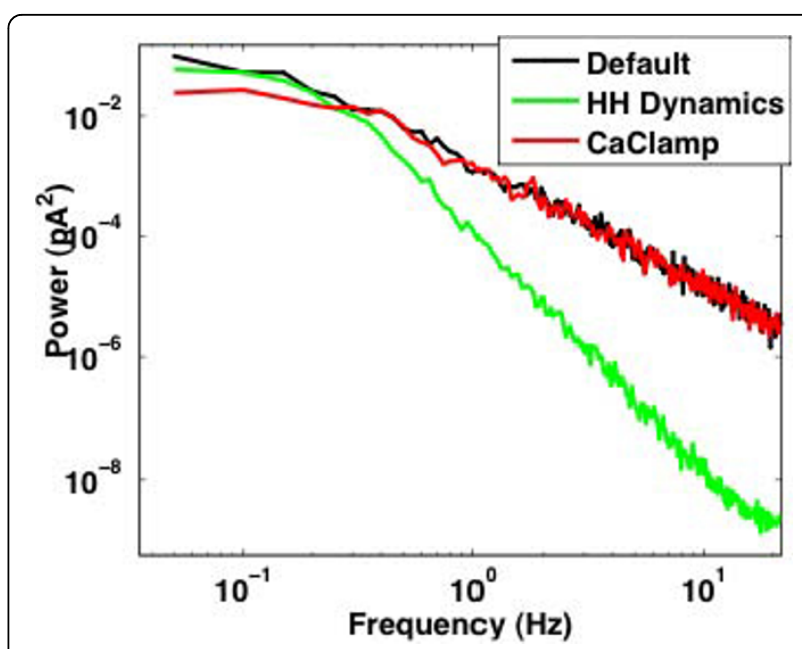

Figure 2 Power spectral density for stochastic $\mathrm{I}_{\mathrm{AHP}}$ current Black trace is simulation under default settings. Red trace shows the effects of clamping intracellular calcium, which reduces lowfrequency power. Green trace shows the IAHP current when inherent thermal fluctuations are removed by switching channel dynamics from Markov to HH. The crossover of these two signals suggests that intracellular calcium fluctuations can contribute to lowfrequency voltage noise. 
Additional modeling has implicated the $\mathrm{Ca}^{2+}$-dependent afterhyperpolarization current $\left(\mathrm{I}_{\mathrm{AHP}}\right)$ as the primary linkage between these two signals. Power spectrum analysis suggests that the contribution of intracellular calcium fluctuations is dominant at low frequencies, below the natural cutoff for $\mathrm{I}_{\mathrm{AHP}}$ noise (Figure 2). We believe that this linkage between membrane potential noise and intracellular calcium could regulate many of the welldocumented roles of noise in the nervous system [1].

\section{Author details}

'Department of Bioengineering, Arizona State University, Tempe, Arizona, 85281, USA. ${ }^{2}$ Institute of Biomaterials and Biomedical Engineering, University of Toronto, Toronto, Ontario, Canada, M5S 3G9. ${ }^{3}$ Naval Surface Warfare

Center, W Bethesda, Maryland, 20817, USA.

Published: 20 July 2010

\section{References}

1. Faisal AA, Selen LPJ, Wolpert DM: Noise in the nervous system. Nature Reviews Neuroscience 2008, 9(4):292.

2. Diba K, Lester HA, Koch C: Intrinsic noise in cultured hippocampal neurons: experiment and modeling. Journal of Neuroscience 2004, 24(43):9723.

3. Traub RD, Jefferys JG, Miles R, Whittington MA, Toth $\mathrm{K}$ : A branching dendritic model of a rodent CA3 pyramidal neurone. J Physiol (Lond.) 1994, 481 (Pt1):79.

4. Strassberg AF, DeFelice LJ: Limitations of the Hodgkin-Huxley formalism: Effects of single channel kinetics on transmembrane voltage dynamics. Neural Comput. 1993, 5(6):843-855.

doi:10.1186/1471-2202-11-S1-P122

Cite this article as: Stanley et al:: Calcium-dependent subthreshold

fluctuations in membrane voltage; a modeling study. BMC Neuroscience 2010 11(Suppl 1):P122.

\section{Submit your next manuscript to BioMed Central} and take full advantage of:

- Convenient online submission

- Thorough peer review

- No space constraints or color figure charges

- Immediate publication on acceptance

- Inclusion in PubMed, CAS, Scopus and Google Scholar

- Research which is freely available for redistribution

Submit your manuscript at www.biomedcentral.com/submit 